\title{
Role of peri-partum counselling in improving choice of postpartum contraception
}

\author{
Vidyadhar B. Bangal*, Sunil Thitame, K. V. Somasundaram
}

Centre for Social Medicine, Pravara Institute of Medical Sciences (Deemed to be University) Loni, Ahmednagar, Maharashtra, India

Received: 23 April 2020

Accepted: 29 May 2020

\section{*Correspondence:}

Dr. Vidyadhar B. Bangal,

E-mail: vbb217@rediffmail.com

Copyright: ( $)$ the author(s), publisher and licensee Medip Academy. This is an open-access article distributed under the terms of the Creative Commons Attribution Non-Commercial License, which permits unrestricted non-commercial use, distribution, and reproduction in any medium, provided the original work is properly cited.

\begin{abstract}
Background: The choice of a contraceptive method is a complex decision. Health care providers have an important role in providing information and supporting patients' decision making about contraceptive choices through counselling. Non-use of contraceptive methods, use of less effective methods, and incorrect and inconsistent use of methods underlie the high frequency of unintended pregnancy. Prospective cross-sectional study was undertaken to study the role of peri-partum counselling in improving choice of postpartum contraception at Pravara Rural Hospital Loni, Ahmednagar, Maharashtra, India.

Methods: Four hundred and fifty women in third trimester of pregnancy were individually counselled about the postpartum contraception, using educational material and pamphlets. The choice of postpartum contraception before and after the counselling was noted.

Results: Among primi gravidas, the most favored choices for postpartum contraception before counselling were condom $(25 \%)$ and lactational amenorrhea method $(12 \%)$. In the same group of women, the post counselling choices were PPIUCD (45\%), condom (17\%) and interval IUCD (7\%). Among multi-gravida, the most favored choices for postpartum contraception before counselling were postpartum tubal ligation (26\%), condom (20\%) and lactational amenorrhea method or calendar method (17\%). In the same group of women, the post counselling choices were postpartum tubal ligation (32\%) PPIUCD (12\%), condom $(8 \%)$.

Conclusions: The study supports the usefulness of good quality counselling both with respect to the interpersonal relationship between the patient and the provider and quality of information that is provided during counselling. Postpartum intrauterine contraceptive device (PPIUCD), a long acting reversible contraceptive, will fulfil the felt need of postpartum contraception in near future.
\end{abstract}

Keywords: Contraceptive choices, Contraceptive counselling, Postpartum contraception, Postpartum intrauterine contraceptive device

\section{INTRODUCTION}

Over the past several decades, the proportion of pregnancies in India that are unintended has remained stubbornly high. This high frequency of unintended pregnancy in India, places a heavy burden on women, their families, and the health care system. Unintended pregnancy is disproportionately experienced by women from different socio economic and minority groups which contribute to the cycle of disadvantage among vulnerable populations. Non-use of contraceptive methods, use of less effective methods, and incorrect and inconsistent use of methods underlie the high frequency of unintended pregnancy. ${ }^{1-3}$ In addition, racial and ethnic differences in contraceptive use contribute to disparities in unintended pregnancy. ${ }^{3,4}$ While use of contraception is influenced by a complex set of factors, including access to medical care and the influence of social networks, providers have the 
potential to positively influence women's ability to use contraception during health care visits, especially as all non-barrier methods of contraception require either a prescription or a medical procedure. Optimizing this counselling is one approach to helping women of all socio-economic strata to improve their ability to plan pregnancies. $^{5}$

Contraception is a women's health issue. It is about choices and human rights, not fear, guilt and shame. The negative images and concepts perceived regarding family planning and contraception in some religious and social arenas are the major factors responsible for noncompliance and meagre usage of birth control methods in many areas of the world. ${ }^{6}$ The choice of a contraceptive method is a complex decision; medical providers have an important role in providing information and supporting patients' decision making about contraceptive methods through contraceptive counselling. ${ }^{7}$

Reproductive health and fertility control counselling is a face to face process of communication in which health care provider (doctor, nurse, counsellor or social worker) help woman, couple or family to identify their needs and to make appropriate reproductive health and fertility control decisions and choices. Counselling is of crucial importance as it guides the clients (men and women) in right direction. Good counselling makes the clients more satisfied and prepared mentally and physically to comply with their decisions and choices. ${ }^{8}$ There is increased receptivity among the women regarding the information provided by the counsellor during peripartum period. Last trimester of pregnancy, pre labour and immediate post labour periods are ideal for counselling regarding contraception. Women or the couple is more likely to accept the advice given by the counsellor. Women in rural area, who are less educated and who have no knowledge about the contraception options are much benefitted through contraceptive counselling services. Present prospective cross-sectional study was undertaken to find out the role of peripartum counselling in improving choice of postpartum contraception at Pravara Rural Hospital Loni, Ahmednagar, Maharashtra, India.

\section{METHODS}

A prospective cross-sectional study was undertaken in the department of obstetrics and gynaecology of Pravara Rural Hospital, Loni, Ahmednagar, Maharashtra, India for a period of six months from July 2019 to December 2019. Pravara Rural Hospital is located in rural area that caters to large population of the district and the neighboring districts. Approximately 9,500-10,000 deliveries take place every year in this hospital. Approximately 4000-4500 antenatal women report to antenatal clinic every month. Four hundred and fifty women in third trimester of pregnancy were individually counselled about the postpartum contraception, using educational material and pamphlets. Individual counselling was "client-centred", rather than "physiciancentred. It was done by trained doctors, nurses or social worker. The counsellors had corrected and up to date information about various contraceptive methods. The six steps of counselling ie "GATHER" were followed as guiding principle. ${ }^{8}$ Good engagement was maintained between women and their providers in the process of method selection. Proper evaluation of the woman's individual reproductive desires, medical complications and other health concerns was done. Consideration was given to life style issues and patient preferences regarding form and route of administration of contraceptive. Other issues that are intensely personal, including relationship influences on contraceptive use, attitudes towards side effects, and desire (or lack of desire) for future fertility were also considered during counselling. The environment during counselling was kept in such a way that the women were able to discuss their concerns and that they receive sufficient information about their options. The choice of postpartum contraception of individual woman before and after counselling was noted. Socio economic and demographic data of individual woman was collected for co-relating it with study observations. Privacy and confidentiality about the information collected was assured to women. Effectiveness of counselling was assessed through the differences in the contraceptive choices before and after counselling. Data was compiled, cleaned and analysed to draw conclusions.

\section{RESULTS}

Four hundred and fifty pregnant women were asked about the choice of postpartum contraception before and after counselling. Average time required for the individual counselling was 10-12 minutes. Women attended the counselling session with enthusiasm. It was observed that forty percent of the pregnant women were below 20 years of age and additional fifty eight percent were between 2030 years of age. Sixty two percent of women had marriage below 20 years of age and twenty eight percent women had marriage in between 20 and 25 years of age. Ten percent women got married after twenty-five years of age. There were $216(48 \%)$ women were primi-gravida and remaining $234(52 \%)$ were multi-gravida. It was observed that fourteen percent of women had education up to fourth, forty two percent had up to tenth class, twenty seven percent had up to higher secondary and seventeen percent women were completed either graduation or post-graduation. Seventy six percent women belonged to middle socio-economic class, fifteen percent to lower class and remaining nine percent to upper class as per modified Kuppuswami classification. Fifty two percent of the pregnant women were involved in farming/agriculture work, twenty seven were involved in domestic work, twelve percent were involved in office work or small business and remaining five percent were involved in professional/service job, mainly as teachers in schools and colleges, security service, telephone operators, bank employee. Fifty-two percent of the 
women counselled belonged to Hindu religion, thirty two percent belonged to Muslim religion, ten percent belonged to Christian and six percent belonged to other religions. Seventy six percent women were residing in rural area (villages) and remaining twenty four percent were residing in urban area (small towns-municipality) or (cities-corporation areas). Seventy eight percent of the women were living in joint family and remaining 22 percent were living in nuclear family (Table 1). The observations regarding the choice of contraception were noted separately for primigravida and multigravida.

Among primi gravidas, the most favoured choices before counselling were condom (25\%) and lactational amenorrhoea method (12\%). Forty percent of the women were didn't respond to the question or were shy to speak on the subject. In the same group of women, the choices for postpartum contraception were different. Most favoured choices were PPIUCD $(45 \%)$, condom $(17 \%)$ and interval IUCD (7\%). Eight percent women did not want to reply about their choice or were shy to answer the question (Table 2).

Among multi-gravida, the most favoured choices before counselling were postpartum tubal ligation (26\%), condom (20\%) and lactational amenorrhoea method or calendar method $(17 \%)$. Thirteen percent of the women were didn't respond to the question or were shy to speak on the subject. In the same group of women, the choices for postpartum contraception were different. Most favoured choices were postpartum tubal ligation (32\%) PPIUCD (12\%), condom (8\%). Twelve percent women did not want to reply about their choice or were shy to answer the question (Table 2).

It was observed that primigravida who belonged to lower socioeconomic class, who were less educated and who had early marriages were either not in position to respond to the question regarding their choice of contraception after delivery. This group of women were either involved in house hold domestic work or were agricultural labourers or were doing work on daily wedges. They were staying in villages and small townships, and had very poor knowledge about contraception. These women had not used any contraception after marriage and were dependant on husband and mother in law for their reproductive decisions.

Multigravida, who had previous one or two children of desired sex combination, were willing for tubectomy operation as permanent contraception. Multigravida, with previous female children, were not willing for permanent contraception and their decision of contraception was dependant on the sex of the baby after delivery. These women told that, if there is male baby, then they might consider to undergo tubectomy operation after delivery. Preference for male child was clearly seen in these women. These women were less educated and from middle and lower socio-economic class and under strong influence of traditions and family norms. Having a male baby was still considered as must in many families in rural area. Women continue to have another pregnancy without spacing for the want of male child.

Table 1: Socio demographic profile of the women.

\begin{tabular}{|ll|}
\hline Socio demographic profile & Percentage of cases \\
\hline Age group & \\
\hline Below 20 & $40 \%$ \\
\hline $20-30$ & $58 \%$ \\
\hline Above 30 & $2 \%$ \\
\hline Age at marriage in years & \\
\hline Below 20 & $62 \%$ \\
\hline $20-25$ & $28 \%$ \\
\hline Above 25 & $10 \%$ \\
\hline Parity & \\
\hline Primi gravida & $48 \%$ \\
\hline Multi gravida & $52 \%$ \\
\hline Education & \\
\hline Primary or less & $14 \%$ \\
\hline Secondary & $42 \%$ \\
\hline Higher secondary & $27 \%$ \\
\hline Graduation and above & $17 \%$ \\
\hline Socio economic class & \\
\hline Lower & $15 \%$ \\
\hline Middle & $76 \%$ \\
\hline Upper & $24 \%$ \\
\hline Occupation & $5 \%$ \\
\hline Domestic work & $52 \%$ \\
\hline Labourer/agriculture work & $52 \%$ \\
\hline Office work/sedentary & $12 \%$ \\
\hline Professional work & $5 \%$ \\
\hline Religion & \\
\hline Hindu & \\
\hline Muslim & \\
\hline Christian & \\
\hline Others & \\
\hline Residence & \\
\hline Rural & \\
\hline Urban & \\
\hline Type of family & \\
\hline Joint & \\
\hline Nuclear & \\
\hline
\end{tabular}

It was observed that $70 \%$ pregnant women were unaware about the newer contraceptive methods like long acting injectable contraceptives and long acting intrauterine contraceptives, thus had not reflected through their initial choice for contraception. Some of them chose these methods as their contraceptive option after receiving information through counselling session. Immediate postpartum IUCD (PPIUCD) was the most favoured long acting reversible contraceptive method, that was chosen by the women after counselling session. The reasons for choosing this method was its longer duration of action, being a reversible method, provided immediately after the delivery thus no need for returning back just for 
contraception purpose, less complications and side effects. This method was preferred by primigravida, who were educated, who could understand its benefits in terms of effectiveness, safety and longer duration.

The traditional, conventional methods like LAM, rhythm method or calendar method were chosen by uneducated or less educated women from villages, who were under strong influence of traditional midwifery. There was significant reduction in percentages of choices made by women for these methods before and after counselling. The main reason for change of preference of method of contraception was unreliability of these methods for protecting them against unwanted pregnancy.

Table 2: Distribution of women as per choice of postpartum contraception before and after counselling.

\begin{tabular}{|lllll|}
\hline Choice of contraception & Primigravida & \multicolumn{2}{l|}{ Multigravida } \\
\hline & $\begin{array}{l}\text { Before } \\
\text { counselling }\end{array}$ & $\begin{array}{l}\text { After } \\
\text { counselling }\end{array}$ & $\begin{array}{l}\text { Before } \\
\text { counselling }\end{array}$ & $\begin{array}{l}\text { After } \\
\text { counselling }\end{array}$ \\
\hline Male condom & 25.00 & 17.00 & 20.00 & 8.00 \\
\hline Mala D/Mala N & 5.00 & 6.00 & 6.00 & 6.00 \\
\hline Interval copper T (375/380A) & 3.00 & 7.00 & 6.00 & 7.00 \\
\hline PPIUCD & 3.00 & 45.00 & 3.00 & 12.00 \\
\hline Saheli (centchroman) & 1.00 & 2.00 & 1.00 & 3.00 \\
\hline Antara (long acting injectable progesterone) & 3.00 & 5.00 & 3.00 & 6.00 \\
\hline Postpartum tubal ligation & 0.00 & 0.00 & 26.00 & 32.00 \\
\hline Interval tubal ligation & 0.00 & 0.00 & 5.00 & 8.00 \\
\hline Vasectomy & 0.00 & 0.00 & 0.00 & 2.00 \\
\hline Lactational amenorrhoea method (LAM) & 12.00 & 6.00 & 9.00 & 4.00 \\
\hline Calendar method/safe period method & 8.00 & 4.00 & 8.00 & 0.00 \\
\hline Unable to decide/confused & 21.00 & 4.00 & 8.00 & 7.00 \\
\hline No response/shy & 19.00 & 4.00 & 5.00 & 5.00 \\
\hline
\end{tabular}

\section{DISCUSSION}

Unwanted pregnancies are not only the major cause of maternal mortality and morbidity, but are also a great social and financial burden on societies and countries. According to WHO statistics, there are an estimated 200 million pregnancies around the world each year, and a third of these, 75 million, are unwanted. These pregnancies contribute to women's health problems in two ways. First, unwanted pregnancy can threaten a woman's health or well-being because she may have existing health problems or lack the support and resources, she needs to have a healthy pregnancy and raise a healthy child. Second, where women do not have access to safe abortion services, many resorts to unsafe procedures that can lead to their death or disability. It is estimated that nearly 80,000 maternal deaths and hundreds of thousands of disabilities occur around the world because of unsafe abortions. ${ }^{6}$

Quality contraceptive counselling has been identified as a potential means to reduce unintended pregnancy and to increase contraceptive continuation and satisfaction. Women's health organizations globally are calling for improved counselling through more thorough discussion of side-effects and bleeding changes, and renewed focus on shared decision making and patient-centred care. A client-centred approach using shared decision making, building trust, and eliciting client preferences has been shown to increase satisfaction and continuation. Clinicians should strive for good interpersonal relationships with patients, and elicit patient experiences and preferences to tailor their counselling to each individual's needs. Shared decision making with input from both the patient and clinician is preferred by many women, and clinicians should be cognizant of perceptions of pushing any method too strongly, especially among marginalized populations. ${ }^{9}$

Improving the quality of contraceptive counselling is one strategy to prevent unintended pregnancy. Researchers have identified aspects of relational and task-oriented communication in family planning care that can assist providers in meeting their patients' needs. Approaches to optimizing women's experiences of contraceptive counselling include working to develop a close, trusting relationship with patients and using a shared decisionmaking approach that focuses on eliciting and responding to patient preferences. Providing counselling about side effects and using strategies to promote contraceptive continuation and adherence can also help optimize women's use of contraception. ${ }^{7}$

A fundamental principle in ethical, female-centred care is that women have a right to participate in their choice of contraceptive method. A woman who has actively chosen 
a method is more likely to use it consistently and correctly. With such a wide range of contraceptive options available, health-care providers face the challenge of matching each patient with the method that is best for her. Proper evaluation of the woman's individual reproductive desires, medical complications and other health concerns is a necessary first step. Consideration should also be given to lifestyle issues and patient preferences regarding form and route of administration. Ultimately, education is the key to compliance, long-term use and success. It is important to address specific concerns of young women to promote compliance. Counselling is essential to provide accurate information about the mechanisms, efficacy and safety of available options. Understanding the needs and characteristics of the individual patient can help the health-care provider to direct her towards the method that will best suit her needs in terms of efficacy, safety and ease of use. ${ }^{6}$

Providing counselling is complicated by the fact that providers and patients must not only consider the medical issues involved in method selection-such as the presence or absence of contraindications to methods and differences in method efficacy - but also consider issues that are intensely personal, including relationship influences on contraceptive use, attitudes towards side effects, and desire (or lack of desire) for future fertility. In addition, there is a need to take in consideration the history in which some family planning providers were involved in coercive efforts to limit vulnerable women's fertility when providing this counseling. ${ }^{10-11}$ Together, these factors result in the provider's role in method selection having the potential to be perceived of differently - by both the patient and the provider - than it would be in other medical decisions. In the area of family planning specifically, the impact of counselling is clearly seen in studies that have found that women's selection of a new contraceptive method is influenced by whether providers mention or recommend specific methods. ${ }^{12,13}$ In addition, there is an evidence supporting the value of both relational and task-oriented communication. Several observational studies in the United States have found a relationship between the interpersonal quality of family planning counselling and contraceptive use. These include two studies that have found that patients who are more satisfied with their family planning visits are more likely to be satisfied with their method, and similarly, that women who are satisfied with their most recent visit to gynecologist visit are more likely to be using contraception. ${ }^{14,15}$ One study in Egypt, using audio recordings of contraceptive counselling visits, found that receiving counselling that was more "client-centred", as opposed to "physician-centred," was associated with continuation of one's chosen method. ${ }^{16}$ In this study, client-centred behaviours were those designed to facilitate women's involvement in the counselling visit, such as statements of partnership, whereas physiciancentred behaviours were those that limited this involvement, such as overt directiveness. In addition, several prospective studies in the developing world have used composite measures of counselling, including measures of both relational and task-oriented aspects of communication, and have found that women who report experiencing higher quality care have higher rates of contraceptive continuation and contraceptive use. ${ }^{17-19}$ Studies have also found that provision of information about side effects specifically is associated with improved outcomes. ${ }^{20,21}$

Studies using observation of family planning encounters have been conducted in both the developing and developed world. With respect to relational communication, these have documented that, across settings, the interaction is often provider-dominated, with minimal engagement between women and their providers in the process of method selection and with frequent failure of providers to deliver personalized counselling tailored to the individual women's needs and preferences. $^{20,22-25}$ Similarly, providers inconsistently engage in such task-oriented communication as providing information about side effects or how to use a method correctly. For example, one study documented that $37 \%$ of women choosing the hormonal IUD were not informed of the likelihood of irregular bleeding with this method, and in a study of counselling about oral contraceptive pills $26 \%$ of women were not given any information about what to do if they forget a pill. ${ }^{24,25}$

Additional studies have used qualitative interviews of both patients and providers to assess their experiences of contraceptive counselling, with respect to both relational and task-oriented communication. These have found that women often report being dissatisfied with their experience of counselling, including feeling that they are unable to discuss their concerns and that they receive insufficient information about their options. ${ }^{26-28}$ Quantitative studies investigating this question have also found that many women express dissatisfaction about the patient-centeredness and adequacy of counseling. ${ }^{15,29-30}$ Other studies have found that providers frequently have inaccurate knowledge about contraceptive methods, including out-of-date information about the safety of IUDs. ${ }^{31-33}$ Overall, these studies support the need for improved counselling about contraceptive methods, both with respect to the interpersonal relationship between the patient and the provider and quality of information that is provided during counselling.

\section{CONCLUSION}

Contraceptive counselling has great potential as a strategy to empower women to choose a method of birth control that she can use correctly and consistently over time, thereby reducing her individual risk of unintended pregnancy. The study supports the usefulness of good quality counselling both with respect to the interpersonal relationship between the patient and the provider and quality of information that is provided during counselling. The contraceptive choices of women depend on various factors and all factors must be kept in mind 
while providing quality contraceptive counselling. Women choose better options of contraception after receiving good up-to-date information and after the opportunity for discussion with the counsellor. There should be adequate counselling facility at all maternity hospitals with the availability of trained counsellor and educational material in multiple languages. Postpartum intrauterine contraceptive device (PPIUCD), a long acting reversible contraceptive, has a promising future as preferred contraceptive method. It will satisfy the felt need of postpartum contraception in near future.

Funding: No funding sources

Conflict of interest: None declared

Ethical approval: The study was approved by the Institutional Ethics Committee

\section{REFERENCES}

1. Mosher W, Jones J. Use of contraception in the United States: 1982-2008. Vital Health Stat. 2010;23:1-44.

2. Kost K, Singh S, Vaughan B, Trussell J, Bankole A. Estimates of contraceptive failure from the 2002 National Survey of Family Growth. Contracept. 2008;77:10-21.

3. Vaughan B, Trussell J, Kost K, Singh S, Jones R. Discontinuation and resumption of contraceptive use: results from the 2002 National Survey of Family Growth. Contracept. 2008;78:271-83.

4. Dehlendorf C, Park SY, Emeremni CA, Comer MD, Vincett MK, Borrero S. Racial/ethnic disparities in contraceptive use: variation by age and women's reproductive experiences. Am J Obstet Gynecol. 2014;210(6):526-e1.

5. Yee L, Simon M. The role of the social network in contraceptive decision-making among young, African American and Latina women. J Adolescent Health. 2011;47:374-80.

6. Luthra R. Contraception counselling and compliance Bulletin World Health Organization; 2007:85:B-C.

7. Dehlendorf C, Krajewski C. Contraceptive counselling: best practices to ensure quality communication and enable effective contraceptive use. Clin Obstet Gynecol. 2014;57(4):659-73.

8. Practice of Fertility control-A comprehensive manual, $7^{\text {th }}$ Edition, S. K. Chaudhary. Published by Elsevier, Reed Elsevier India Private Limited, New Delhi; 2017:18.

9. Schivone G. Contraceptive counseling for continuation and satisfaction. Curr Opin Obstet Gynecol. 2017;29(6):443-8.

10. Stern AM. Sterilized in the name of public health: race, immigration, and reproductive control in modern California. Am J Public Health. 2005;95:1128-38.

11. Roberts D. Killing the black body: race, reproduction, and the meaning of liberty. Pantheon Books; New York, NY; 1997.
12. Harper CC, Brown BA, Foster-Rosales A, Raine TR. Hormonal contraceptive method choice among young, low-income women: how important is the provider? Patient Educat Counseling. 2010;81:34954.

13. Bitzer J, Cupanik V, Fait T, Gemzell-Danielsson K, Grob P, Oddens BJ, et al. Factors influencing women's selection of combined hormonal contraceptive methods after counselling in 11 countries: results from a subanalysis of the CHOICE study. Eur J Contracept Reprod Health Care. 2013;18(5):372-80.

14. Rosenberg MJ, Waugh MS, Burnhill MS. Compliance, counseling and satisfaction with oral contraceptives: a prospective evaluation. Fam Plann Perspect. 1998;30:89-92.

15. Forrest JD, Frost JJ. The family planning attitudes and experiences of low-income women. Fam Plann Perspect. 1996;28:246-55.

16. Abdel-Tawab N, Roter D. The relevance of clientcentered communication to family planning settings in developing countries: lessons from the Egyptian experience. Soc Sci Med. 2002;54:1357-68.

17. Koenig MA, Hossain MB, Whittaker M. The influence of quality of care upon contraceptive use in rural Bangladesh. Stud Fam Plann. 1997;28:278-89.

18. RamaRao S, Lacuesta M, Costello M, Pangolibay B, Jones $\mathrm{H}$. The link between quality of care and contraceptive use. Int Fam Plan Perspect. 2003;29:76-83.

19. Sanogo D, RamaRao S, Jones H, N'Diaye P, M'Bow B, Diop CB. Improving quality of care and use of contraceptives in Senegal. Afr J Reprod Health. 2003;7:57-73

20. Backman T, Huhtala S, Luoto R, Tuominen J, Rauramo I, Koskenvuo M. Advance information improves user satisfaction with the levonorgestrel intrauterine system. Obstet Gynecol. 2002;99:608-13

21. Canto De Cetina TE, Canto P, Ordonez Luna M. Effect of counseling to improve compliance in Mexican women receiving depotmedroxyprogesterone acetate. Contracept. 2001;63:143-6.

22. Kim YM, Kols A, Bonnin C, Richardson P, Roter D. Client communication behaviors with health care providers in Indonesia. Patient Educ Couns. 2001;45:59-68.

23. Dehlendorf C, Kimport K, Levy K, Steinauer J. A qualitative analysis of approaches to contraceptive counseling. Perspect Sex Reprod Health. 2014;46(4)233-40.

24. Peremans L, Rethans JJ, Verhoeven V, Debaene L, Van Royen P, Denekens J. Adolescents demanding a good contraceptive: a study with standardized patients in general practices. Contracept. 2005;71:421-5.

25. Dehlendorf C, Tharayil M, Anderson N, Gbenedio K, Wittman A, Steinauer J. Counseling About IUDs: A Mixed-Methods Analysis. Perspect Sex Reprod Health. 2014;46(3):133-40. 
26. Guendelman S, Denny C, Mauldon J, Chetkovich C. Perceptions of hormonal contraceptive safety and side effects among low-income Latina and nonLatina women. Matern Child Health J. 2000;4:233-9.

27. Yee LM, Simon MA. Perceptions of coercion, discrimination and other negative experiences in postpartum contraceptive counseling for low-income minority women. J Health Care Poor Underserved. 2011;22:1387-400.

28. Dehlendorf C, Levy K, Kelley A, Grumbach K, Steinauer J. Women's preferences for contraceptive counseling and decision making. Contracept. 2013;88(2):250-6.

29. Becker D, Koenig MA, Kim YM, Cardona K, Sonenstein FL. The quality of family planning services in the United States: findings from a literature review. Perspect Sex Reprod Health. 2007;39:206-15.

30. Becker D, Tsui AO. Reproductive health service preferences and perceptions of quality among lowincome women: racial, ethnic and language group differences. Perspect Sex Reprod Health. 2008;40:202-11.

31. Dehlendorf C, Levy K, Ruskin R, Steinauer J. Health care providers' knowledge about contraceptive evidence: a barrier to quality family planning care? Contracept. 2010;81:292-8.

32. Harper CC, Blum M, de Bocanegra HT. Challenges in translating evidence to practice: the provision of intrauterine contraception. Obstet Gynecol. 2008;111:1359-69.

33. Schreiber CA, Harwood BJ, Switzer GE, Creinin MD, Reeves MF, Ness RB. Training and attitudes about contraceptive management across primary care specialties: a survey of graduating residents. Contracept. 2006;73:618-22.

Cite this article as: Bangal VB, Thitame $S$,

Somasundaram KV. Role of peri-partum counselling in improving choice of postpartum contraception. Int J Reprod Contracept Obstet Gynecol 2020;9:301824. 